IMPLANT THERAPY OUTCOMES, SURGICAL ASPECTS

\section{Clinical parameters of implants placed in healed sites using flapped and flapless techniques: A systematic review}

Oscar Llamas Monteagudo, Paula Girbés Ballester, Pepe Viña Almunia, David Peñarrocha Oltra, Miguel Peñarrocha Diago.

Master in Oral Surgery and Implant Dentistry. Faculty of Medicine and Dentistry, University of Valencia,

\section{Background and Aim}

Dental implant placement using flapless surgery is a minimally invasive technique that allows a reduction in surgical time, minimum disruption of peri-implant tissues and decreased postoperative bleeding. However, significant disadvantages of flapless placement include the inability to visualize anatomic landmarks and vital structures, and it does not provide access to allow bone regeneration.

The aim of this systematic review was to evaluate the clinical parameters following implant surgery in healed sites, using two procedures: flapped vs. flapless surgery.

\section{Methods and Materials}

A detailed electronic search was carried out in the PubMed/Medline, Embase and Cochrane Library databases. The focused question was, "How do flapped and flapless surgical techniques affect the clinical parameters of dental implants placed in healed sites?". All the studies included with a prospective controlled design were considered separately, depending on whether they had been conducted on animals or humans. The following data were recorded in all the included studies: number of implants, failures, location (maxilla, mandible), type of rehabilitation (partial or single), followup and flap design.

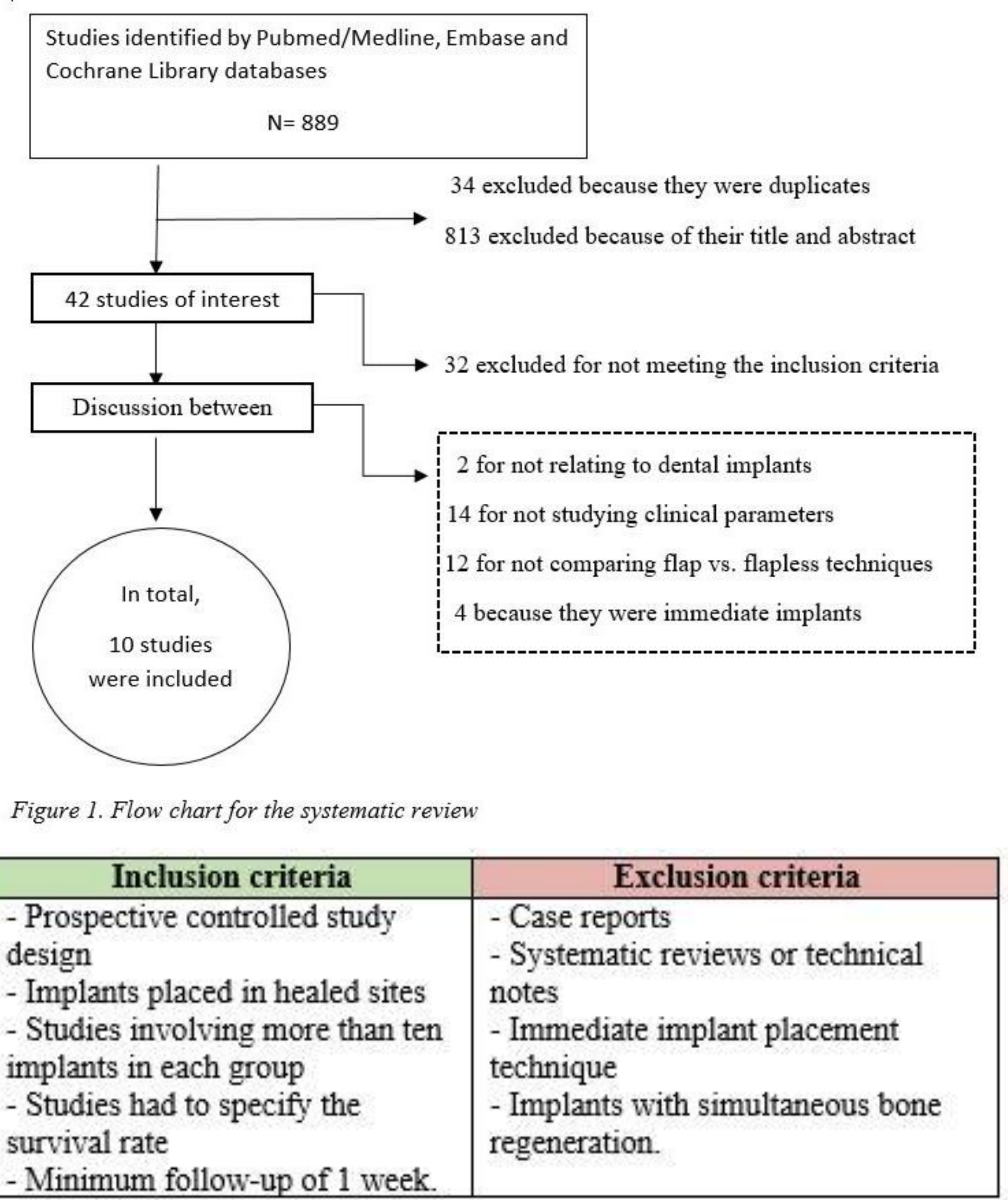

\section{Results}

The following data were recorded in all the included studies: number of implants, failures, location (maxilla, mandible), type of rehabilitation (partial or single), follow-up and flap design. The variables selected for comparison in the animal studies were the following: flap design, gingival index, mucosal height, recession and probing pocket depth. In humans studies the variables were as follows: flap design, plaque index, gingival index, recession, probing pocket depth, papilla index and keratinized gingiva.
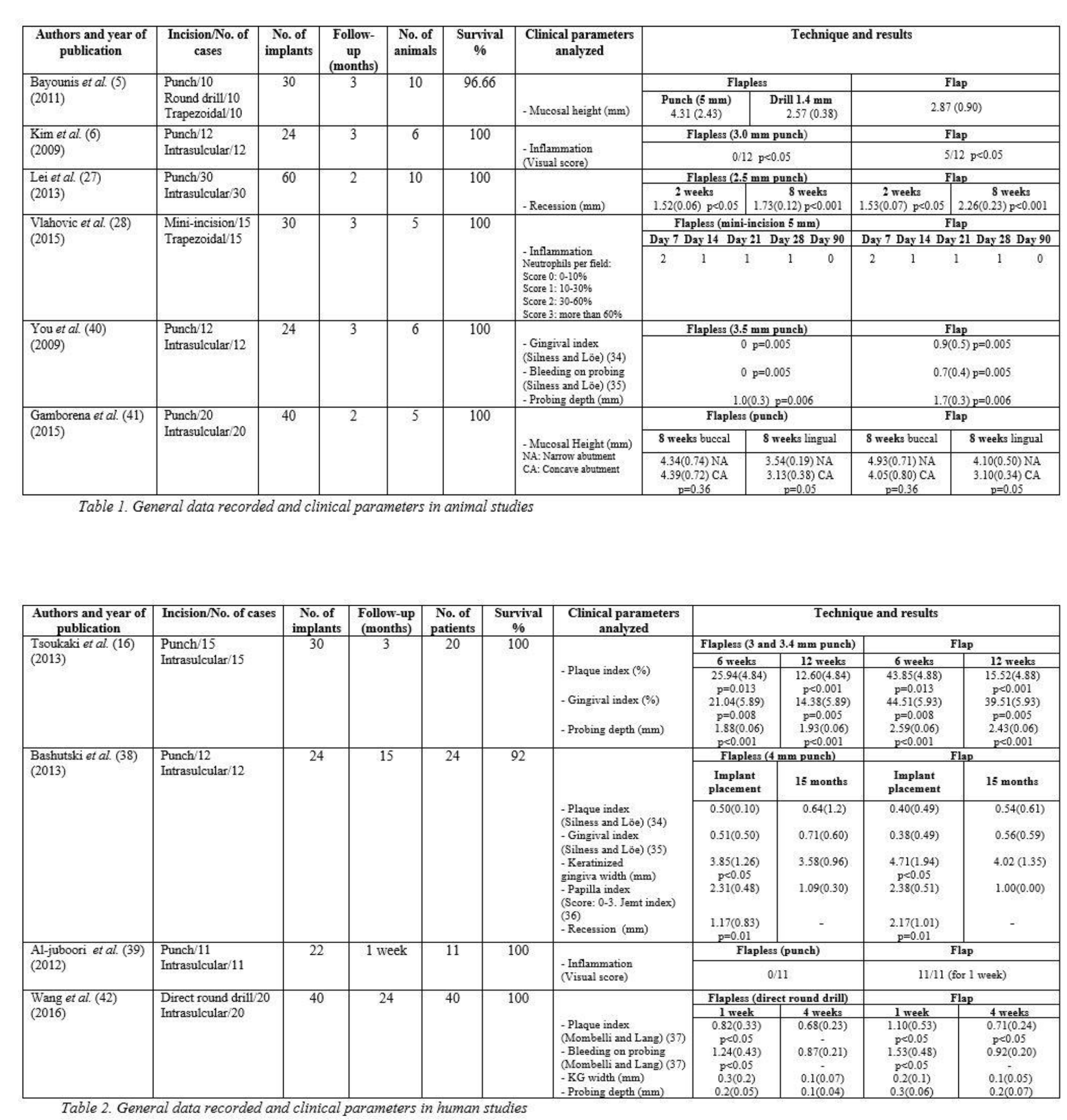

\section{Conclusions}

The animal studies included in the present review show that implants placed in healed sites with a flapless approach have better clinical parameters than the flapped procedure in a short-term follow-up. In human studies, there is no consensus about which technique offer better results in terms of clinical parameters.

\section{References}

1. Bayounis AMA, Alzoman HA, Jansen JA, Babay N. Healing of peri-implan tissues after flapless and flapped implant installation. J Clin Periodontol. tissues after llapless

2. Campelo LD, Camara JR. Flapless implant surgery: A 10-year clinical retrospective analysis. Int J Oral Maxillofac Implants. 2002;17:271-276.

3. Jeong, SM., Choi, BH., Li, J., Kim, HS., Ko, CY., Jung, JH., Lee, HJ., Lee, SH. \& Engelke, W. Flapless implant surgery: an experimental study. Ora Surgery.2007;104, 24-28.

4. Becker, W., Goldstein, M., Becker, B. E. \& Sennerby, L. Minimally invasive flapless implant surgery: a prospective multicenter study. Clinical Implant and Dentistry. 2005; Research 7, 21-27. 